\title{
On the Paradox of Collaboration, Collaborative Systems and Collaborative Networks
}

\author{
Donald Neumann \\ Graduate School of Excellence for Advanced Manufacturing Engineering, \\ University of Stuttgart, Keplerstr. 17, R10.027, 70174, Stuttgart, Germany \\ donald.neumann@gsame.uni-stuttgart.de
}

\begin{abstract}
It has been claimed that collaborative networks are the societal structure of this century. Nonetheless, low success rates often observed in the practice of purposeful collaboration suggest that our understanding is still limited. In this paper, I advance on the theory of collaborative systems, a systems theoretical approach to interorganizational collaborative relationships, critically investigating their nature. Based on the characteristics of social systems, I suggest an explanation to the low success rates observed in practice. Furthermore, I offer an alternative definition of collaborative networks according to the theory presented and discuss some implications and challenges to the discipline of Collaborative Networks.
\end{abstract}

Keywords: Systems Theory, Collaborative Systems, Collaborative Networks, Interorganziational Collaborative Relationships, Social Systems.

\section{Introduction}

The history of society is the history of how individuals communicate and join forces to pursue goals in a coordinated way [13], 'collaborating' in the broadest sense of the term. Hence, the evolution to a functionally differentiated society, in which social systems (e.g. politics, law, and economy) fulfill different societal functions autonomously [13], cannot be distinguished from the evolution of collaboration among individuals. Interorganizational collaborative networks emerged from the recognition of the potential of coordination and collaboration among organizations and have been claimed to be the 'societal structure of the $21^{\text {st. }}$ century' [19].

Interorganizational collaborative relationships are not a new phenomenon though. Artisans probably worked together to increase product complexity and production capacity. Nonetheless, these relationships gained momentum in academia only in the past 50 years [19]. Thereby, interorganizational collaborative relationships, defined broadly as "voluntary interactions among autonomous organizations that are not strictly based on economic transactions" [16], have been studied under different labels, for example, 'Collaborative Relationships', 'Strategic Alliances' and 'Collaborative Networks'. 
Different economic benefits have been associated with collaboration [9]. Nevertheless, high failure rates have been systematically reported [10]. This fact suggests an apparent paradox of collaboration: while the success of social systems in fulfilling their function relies on the almost intuitive communication and coordination of actions among individuals, organizations strive to achieve the potential of collaboration. Thus, it seems that our understanding of interorganizational collaboration is either incomplete or incompatible with the properties of collaboration among individuals in society.

Seeking to offer an innovative explanation to this paradox, in this work I abstract from specific forms of collaborative relationships. Therefore, in section 2 I analyze existing theoretical perspectives on collaboration, highlighting their limitations. Advancing on the investigation of the nature of interorganizational collaborative relationships, in section 3 I further develop the theory of collaborative systems and offer an explanation to the high failure rates observed in practice. In section $4 \mathrm{I}$ discuss the main implications of collaborative systems to the practice and the discipline of collaborative networks, offering an alternative definition of collaborative networks. Finally, in section 5, I conclude, highlighting some possible extensions of this work.

\section{Collaborative Relationships}

Interorganizational collaborative relationships have been investigated from different perspectives. Focusing on the properties of competitive markets, Neoclassical Economics interprets firms as rational agents who compete for market power. This tradition is translated in Porter's well-known Five Forces Model [18]. Collaborative relationships are described as interactions among competitors concerning prices and quantities, allowing firms to create monopoly rents. Nonetheless, rationality assumptions suggest that firms are expected to maximize individual profits at the expense of joint ones [20]. Consequently, collaborative relationships tend to be unstable, characterized by competitive and opportunistic behavior.

Transaction Costs Economics (TCE) explains a firm's choice among markets, hierarchies and hybrids as equivalent forms of coordinating transactions [24]. Markets accomplish this function through output-based rewards and hierarchies through inputbased ones ruled by employment contracts. Collaborative relationships are hybrid governance mechanisms that involve both output- and input-based rewards structured by incomplete, long-term contracts [24]. Assuming that transactions differ on assetspecificity, uncertainty and frequency, TCE asserts that the choice of the governance forms is contingent on the costs resulting from the match between transactions properties and governance form. Similarly to Neoclassical Economics, TCE describes firms as rational agents that maximize individual gains. Thus, opportunistic behavior is expected and hybrids are competitive unstable governance forms [15].

The Resource-Based View of the firm (RBV) and its derivations describe the firm as a bundle of resources from which a subset, the strategic ones, allows it to sustain competitive advantage [12]. Assuming that firms interact with their environment in 
order to acquire resources, collaborative relationships are described either as a means to access resources or as strategic resources themselves [5]. Consequently, RBV suggests that collaborative relationships are strategies capable of generating and sustaining competitive advantage [7].

Supply Chain Management (SCM) focuses on the flows of information and goods between and among firms [23]. Collaborative relationships are characterized by the communication of decisions about demand, supply and stock. By allowing the production and flow of goods to be coordinated [6], collaborative relationships are described as the rational choice and hence cooperative behavior is expected.

Game Theory and Principal-Agent Theory focus on interactions among players, in which the outcomes depend on the decisions made by players individually [22]. Offering a set of mathematical tools to analyze strategic situations, these theories highlight the connection between decisions under a specific set of expectation structures. Based on the prediction of a partner's response, these models suggest adequate decisions, thereby absorbing decision uncertainty [2]. Collaborative relationships are thereby described as a set of repeated interactions according to known expectations structures [17]. In spite of rationality assumptions, outcomes are not restricted to (but nonetheless are mainly described as) economic ones and relationships may assume either a cooperative or competitive nature, depending on the rules of the game.

Social Network Analysis (SNA) approaches the network of actors constituted by multiple relationships [25]. Similarly to Game Theory, SNA does not constitute a theory itself, but rather a set of mathematical tools. In the realm of interorganizational networks, SNA researchers have focused mainly on the relation between the structure of the network and their benefits, i.e. social capital [25]. Thereby it is assumed that the structure of the network changes the level of access and control over information, resulting in different performance [11]. Consequently, SNA abstracts from specific collaborative relationships focusing on the totality of relationships in the network.

Each theory mentioned above offers a different model for collaborative relationship. Nonetheless, they share three common properties that affect how these relationships are understood.

1. Incompatible goals: each one of the mentioned theories was motivated by the explanation of phenomena other than collaborative relationships. Consequently, although these theories explain collaborative relationships, these explanations remain partial and constrained by the theories' original (mainly, if not strictly, economic) motives and goals.

2. Incompatible unit of study: these theories focus on units of study other than the collaborative relationship itself. For instance, while TCE approaches transactions, RBV investigates resources, Game Theory specific decisions, and networks abstract from the relationships themselves. Consequently, collaborative relationships are explained partially and in reference to the respective unit of study.

3. Focus on content, not nature: finally, the theories described above do not approach the nature of collaborative relationships. Rather, they approach the content and behavior of specific types of relationships (e.g. Strategic Alliances). 
Consequently, the theories briefly described above seem to miss the point. They investigate the motives, consequences and properties of collaborative relationships without describing their nature, i.e. the mechanisms that allow these behaviors to emerge in the first place. Hence, they "are often used to make predictions, yet they do not provide explanations" [1]. Together, these properties contribute to a partial and incomplete understanding of collaboration, limiting the understanding of high failure rates observed in practice. Consequently, as highlighted by [3], an "urgent need to establish a sound theoretical foundation for $\mathrm{CNs}$ " has been already identified in the discipline of Collaborative Networks.

As proposed by [3], Collaborative Networks $(\mathrm{CN})$ constitutes a discipline that covers different forms of interorganizational collaborative relationships. A research community that identifies itself with the object of study 'collaborative networks' and an already organized set of basic knowledge characterizes it as a discipline. Thereby, 'collaborative network' is defined as a network "constituted by a variety of entities (e.g., organizations and people) that are largely autonomous, geographically distributed, and heterogeneous in terms of their: operating environment, culture, social capital, and goals. Nevertheless these entities collaborate to better achieve common or compatible goals, and whose interactions are supported by computer network." While this ontological definition is useful for modeling purposes, it is not related with any underlying theory about the social and organizational nature of these relationships. Thus, even though it offers some guidance for researchers in the discipline of Collaborative Networks, by ignoring the fact that a structured nexus of communications, i.e. a social system, is necessarily a constitutive part of such a network, it restricts the advancement of knowledge about the social structure and organizational behavior of these networks.

\section{Collaborative Systems}

Instead of describing collaborative relationships as a rational means to an end, I follow [16] and advance on collaborative relationships from the perspective of social systems theory. Functionally, collaborative relationships provide organizations with information that [16]:

1. Can be adopted as a decision, absorbing uncertainty and thereby offering a solution to an organizational problem.

2. By functioning as a decision premise conditions further decisions.

When fulfilling these functions for every partner, collaborative relationships structurally couple partners, allowing them to co-adapt. Thus, these relationships stabilize (i.e. succeed) if and only if they contribute to absorb uncertainty and reduce complexity. This functional approach differs from the ontological definition of collaborative network. In this context, an interorganizational relationship constitutes a collaborative system only if the function of collaboration is fulfilled and recognized as being fulfilled by the relationship itself. 
In order to fulfill this function, organizations 'organize their relationship', i.e. they decide about the expectations about the relationship itself. When these decisions condensate into decision premises that structure further collaborative decisions, an autopoietic network of collaborative decisions emerges and the relationship becomes a social system of the type organization: the 'Collaborative System'. Thus, generalizing the proposition offered in [16], I propose:

Proposition 1. A collaborative system is an organization system that fulfills the organizational function of collaboration.

As in the case of social systems, the basal element of collaborative systems is a specific type of communication. Furthermore, as an organization system, collaborative systems are reproduced by the communication of decisions (in this case collaborative decisions) among partners (the organizations recognized by the collaborative system as members). This definition widens and therefore includes the definition presented in [16]. Consequently, even though a collaborative system structurally couples partners allowing them to co-adapt structures (decision premises), the boundaries of partners and the boundaries of the collaborative system remain clear. For in a collaborative relationship (or, specifically, in a collaborative network) each decision is clearly identified either as a decision of the relationship or a partner's one.

Differently from organization systems in general, collaborative systems are included in the specific context of interorganizational relationships. Thereby they recognize their partners as the main source of resources. This resource dependence allows partners to influence collaborative systems by choosing specific members and by restricting topics to those of actual interest. Nonetheless, collaborative systems remain autonomous. Thus, even though a partner may try to influence the relationship in a specific direction, it cannot force the relationship to respond. This decision remains a decision of the collaborative system. This autonomy is the result of operational closure and implies that the organizational network of decisions neither generates collaborative decisions nor control them as causal function of organizational ones.

There are two direct consequences of operational closure. First, a partner cannot influence another one directly. Therefore, he needs first to influence the collaborative system through communicating about collaborative decisions. This necessarily indirect path increases the probability that influence or control attempts will fail. Second, as social systems collaborative systems cannot be controlled externally. As the experience with communism and political regulation of markets show, organizations (as any other social system) interpret their environment according to their internal structure and state. Consequently, even though environmental events influence organizations, the organizational reaction is not causal. Thus, management is an internal function of the system. Similarly, collaborative systems cannot be installed, controlled or managed [16]. In fact, the effort to control a collaborative system often relies on communication of power, breaking expectation structures such as trust, eventually destroying the relationship as a whole [26]. 
Collaborative systems contribute to the advancement of knowledge about collaborative relationships, hence collaborative networks, in different ways. First, collaborative systems are coherent with a theory of communication and coordination in society. Unlike the concepts presented in the previous section, it is motivated by the study of the behavior that emerges from the basal operation and structure of collaborative relationships. Therefore, organizations are not reduced to firms as production functions, bundles of resources or governance forms that emerge rationally because it is cheaper to produce than to buy. Organizations are recognized as complex societal achievements, resulting from the co-evolution of complementary social systems as forms of structural coupling among organisms in the social domain. Consequently, collaborative systems complement social systems theory by describing the communication and coordination of decisions between and among organizations.

Second, collaborative systems describe collaborative relationship as an indivisible unit of study, highlighting the nature and the specific characteristics of these relationships. Based on the organizational function of collaboration, collaborative systems explain how organizations become coupled through a structured network of communications, namely, collaborative decisions. Thereby, collaborative systems offer a clear-cut description of the nature and structure of collaborative relationships, without being restricted by content. Thus, collaborative systems complement the discipline of Collaborative Networks by specifying the social and organizational nature of collaborative networks.

Third, based on the distinction between system and environment, collaborative systems do not assume a specific context, e.g. the economic or the political one. Consequently, the theory is general and valid for any type of collaborative relationship. In fact, the context independence highlights the potential societal role of collaborative relationships. As a result of societal functional differentiation, organizations are expected to operate simultaneously according to different and potentially contradictory expectations, e.g. economic, social, political and ecological. Collaboration is a potential solution for this problem [21], allowing organizations to coordinate decisions in the context of different function systems. Thus, in order to develop the full potential of collaboration, a respective general model is necessary, including, but not exclusively, the economic context.

Fourth, collaborative systems suggest an answer to high failure rates observed in practice. As emergent, autopoietic networks of communications structured by expectations, collaborative systems constitute the social domain of organizations, in which meaning is constructed through recursive communications about collaborative decisions. Consequently, collaborative systems are dependent on history and exist only while collaborative decisions are (re-)produced. Paraphrasing [14] 'only collaborative decisions decide about collaboration.' Structure emerges as eigenvalues of the system, i.e. as stable expectation structures in the relationship, that constantly change and are changed by collaborative decisions.

Nonetheless, collaborative systems are rarely understood as autonomous systems, capable of managing themselves. Rather, the approaches mentioned in section 2 describe collaborative relationships as controllable input-output systems. Consequently, partners seek to develop management best practices and information 
systems in an effort to better control the relationship. Thereby organizations often constrain the evolution of the system, contributing to the emergence of conflict, hindering the fulfillment of the function of collaboration.

Even though standards and best practices fulfill a similar function as language, i.e. they constitute symbols for generalized meaning, they are not meaning itself. Consequently, collaborative systems cannot be installed and regulated through the simple use of standards and information systems. Because organizations are operationally closed systems, the meaning of these standards is a construction of the system itself that cannot be transferred from one system to another (e.g. from organization to collaboration). Nonetheless, in the quest to achieve the potential (economic) results of collaboration, organizations often rush to adopt standards, processes and key performance indicators. Thereby, they overlook the fact that standards acquire meaning through collaborative decisions in the collaborative system and not the other way around.

\section{$4 \quad$ Implications}

Underlying the theories presented in section 2 is the assumption that collaborative relationships are controllable input-output systems. As social systems instead, they tend to draw "our attention to the very points at which an attempt to intervene will fail" [8]. Counter-intuitively, by seeking better ways of 'managing the relationship' partners impede collaborative systems to manage themselves and, thereby, succeed. Thus, collaborative systems suggest an analogy between collaborative relationships and firms. Even though this analogy is imperfect, the metaphor is useful for better understanding collaborative systems. Thus, as firms, collaborative systems are organization systems in their own right, even though they need not be legal institutions. Furthermore, collaborative systems offer a product to a set of clients, the partners, and also have a set of suppliers, again their partners, who provide them with the necessary resources.

The firm analogy has important consequences for the practice of collaboration. Although partners have the choice of engaging in a collaborative relationship, they do not have the choice of controlling or managing it in the cybernetic sense. Collaborative relationships are evolutionary systems, whose structure, identity and management emerge from their ongoing autonomous operation. Partners can only influence this process in two ways. As their suppliers, partners influence collaborative relationships through the control of resources. As clients, partners establish the raison d'etre of the collaborative system expecting from them a product of (not necessarily economic) value that translates the specific function of collaboration. Last, but not least, just as in any organization, collaborative relationships are able to autonomously decide about their resources in order to provide their services. Because collaborative systems cannot be controlled, after clearly defining suppliers, clients and products, partners should let management emerge in the collaborative system as a function of its operation (the relationship). In fact, the one-sided imposition of decisions to the 
relationship highlights its lack of autonomy. The consequence may be the deterioration to game playing following an exclusively economic rationality.

In the specific context of collaborative supply chains and in accordance with the model proposed in this work, [4] highlight that "firms' efforts to manage supply chains have often led to frustration and helplessness. Managers have struggled with the dynamic and complex nature of supply networks [collaborative relationships] and the inevitable lack of prediction and control." Consequently, the firm analogy backs up the authors' conclusion that 'clearly, 'good intention' is not enough. Managers must possess a mental model of supply networks [collaborative relationship] that more accurately reflects its true underlying complexity and dynamism" [4].

Finally, collaborative systems have an important implication to the research and discipline of Collaborative Networks. Describing the function and nature of interorganizational collaborative relationships as a specific type of organization system, collaborative systems suggest a revision of the strictly ontological definition of collaborative networks offered in [3]. Reviewing this definition according to the theory presented here, a collaborative network is properly defined as:

Proposition 2. A collaborative network is a collaborative system that allows its members to achieve common or compatible goals and whose communications are supported by a computer network.

According to social systems theory, social systems are idiosyncratic and, therefore, the members of the collaborative system are intrinsically understood as heterogeneous in terms of their structures, which include goals, organizational culture, hierarchy, etc. Furthermore, by restricting collaborative networks to collaborative systems, it is assumed that collaborative networks fulfill the function of collaboration. Thus, collaborative networks describe themselves as indivisible wholes, as a relationship among organizations that is capable of fulfilling the function of collaboration for every partner and, thus, couples them structurally. Moreover, in the specific case of collaborative networks, this function is translated into common or compatible goals and a computer network supports the interaction, i.e. the communication about collaborative decisions. Consequently, according to this definition, every collaborative network necessarily involves a collaborative system, even though a collaborative system is not necessarily a collaborative network. For instance, in price collusions among competitors the function of collaboration is fulfilled through the communication about prices, even though there is no decision about common or compatible goals and no computer network is therefore required.

In contrast to the original definition, the alternative definition proposed here maintains important ontological characteristics but explicitly includes the social nature of collaboration, highlighting collaborative networks as autonomous organization systems. Thereby it suggests an extension of research towards an organizational theory of collaborative networks, contributing to close the existent lack of theoretical foundation for collaborative networks highlighted in [3]. Thereby, collaborative systems establish a link between organizational theory and collaborative networks, allowing the latter to formally benefit from the knowledge already existent. For instance, social systems theory, theories of leadership, organizational culture, 
behavior, change and learning can be transported into the realm of collaborative networks, contributing to a greater understanding of the phenomenon. Furthermore, by establishing important differences between the context of organizations in general and collaborative relationships specifically, collaborative systems suggest a starting point to adapt organizational theories to the specific case of collaborative networks. Last, but not least, by being independent of a specific context (e.g. economy), collaborative systems formally include collaborative relationships between different types of organizations, for instance, political parties, NGOs, universities and firms. Thereby, it offers a general framework to study collaborative networks and their role in addressing emerging societal challenges.

\section{Conclusions and Future Work}

This work extended the concept of collaborative systems. Describing interorganizational collaborative relationships as social systems of the type organization, it was suggested that, in contrast to collaboration among individuals, firms strive to control the uncontrollable, i.e. their relationships, allowing the apparent paradox of collaboration to emerge. Drawing on the properties of social systems, an analogy between collaborative systems and firms was presented, explaining how the understanding of these systems can help increase success rates. Finally, an alternative definition for the concept of collaborative network was offered, which explicitly highlights the social nature of these networks turning the concept coherent with a theory of organizations and society.

Even though this work builds on the concept of collaborative systems presented in [16], it is only a small step towards a theory of interorganizational collaborative relationships in general and collaborative networks specifically. Consequently, several extensions of this work are possible. First, future work should be dedicated to further detail collaborative systems, relating them to and distinguishing them from organizations in general, according to existent organizational theory. Second, the role of power, contracts, trust and reputation in collaborative systems should be investigated. Third, the theory of collaborative systems should be extended to detail the evolution of these systems in contrast to the evolution of organizations in general, describing the common life cycle of collaborative relationships. Finally, existent methods and information systems to support collaboration could be evaluated and adapted according to the theoretical proposition described in the last section.

\section{References}

1. Bacharach, S.B.: Organizational theories: some criteria for evaluation. The Academy of Management Review 14(4), 496-515 (1989)

2. Baiman, S., Rajan, M.V.: Incentive issues in inter-firm relationships. Accounting, Organizations and Society 27(3), 213-238 (2002) 
3. Camarinha-Matos, L.M., Afsarmanesh, H.: Collaborative networks: a new scientific discipline. Journal of Intelligent Manufacturing 16(4-5), 439-452 (2005)

4. Choi, T.Y., Dooley, K.J., Rungtusanatham, M.: Supply networks and complex adaptive systems: control versus emergence. Journal of Operations Management 19(3), 351-366 (2001)

5. Das, T., Teng, B.: A resource-based theory of strategic alliances. Journal of Management 26(1), 31-61 (2000)

6. Datta, P.P., Christopher, M.G.: Information sharing and coordination mechanisms for managing uncertainty in supply chains: a simulation study. International Journal of Production Research 49(3), 765-803 (2011)

7. Dyer, J.H., Singh, H.: The Relational View: cooperative strategy and sources of interorganizational competitive advantage. The Academy of Management Review 23(4), 660-679 (1998)

8. Forrester, J.W.: Counterintuitive behavior of social systems. Theory and Decision 2, 109140 (1971)

9. Gulati, R.: Managing Network Resources. Oxford University Press, Inc., New York (2007)

10. Kapmeier, F.: Common learning and opportunistic behaviour in learning alliances. Systems Research and Behavioral Science 25, 549-573 (2008)

11. Kilduff, M., Brass, D.J.: Organizational social network research: core ideas and key debates. The Academy of Management Annals 4(1), 317-357 (2010)

12. Lockett, A., Thompson, S., Morgenstern, U.: The development of the Resource-Based View of the Firm: a critical appraisal. International Journal of Management Reviews 11(1), 9-28 (2009)

13. Luhmann, N.: Die Gesellschaft der Gesellschaft, Suhrkamp, Frankfurt am Main, Germany (1998)

14. Luhmann, N.: Die Form 'Person'. In: Soziologische Aufklärung 6: Die Soziologie und der Mensch, 3rd edn., pp. 137-148. VS Verlag, Wiesbaden, Germany (2009)

15. Ménard, C.: Hybrid organizations. In: Klein, P., Sykuta, M. (eds.) The Elgar Companion to Transaction Cost Economics, pp. 176-184. E. Elgar, Cheltenham (2011)

16. Neumann, D., de Santa-Eulalia, L.A., Zahn, E.: Towards a Theory of Collaborative Systems. In: Camarinha-Matos, L.M., Pereira-Klen, A., Afsarmanesh, H. (eds.) PRO-VE 2011. IFIP AICT, vol. 362, pp. 306-313. Springer, Heidelberg (2011)

17. Parkhe, A.: Strategic alliance structuring: a game theoretic and transaction cost examination of interfirm cooperation. The Academy of Management Journal 36(4), 794829 (1993)

18. Porter, M.E.: The five competitive forces that shape strategy. Harvard Business Review 86(1), 78-93 (2008)

19. Raab, J., Kenis, P.: Heading toward a society of networks: empirical developments and theoretical challenges. Journal of Management Inquiry 18(3), 198-210 (2009)

20. Samuelson, P.A., Nordhaus, W.D.: Economics, 18th edn. McGraw-Hill International Edition, New York (2005)

21. Senge, P., Smith, B., Kruschwitz, N., Laur, J., Schley, S.: The Necessary Revolution, 2nd edn. Nicholas Brealey Publishing, London (2010)

22. Sotomayor, M.: Introduction to game theory. In: Meyers, R.A. (ed.) Encyclopedia of Complexity and Systems Science, pp. 4095-4097. Springer (2009)

23. Stock, J.R., Boyer, S.L.: Developing a consensus definition of supply chain management: a qualitative study. International Journal of Physical Distribution \& Logistics Management 39, 690-711 (2009) 
24. Williamson, O.: Comparative economic organization: the analysis of discrete structural alternatives. Administrative Science Quarterly 36(2), 269-296 (1991)

25. Zaheer, A., Gözübüyük, R., Milanov, H.: It's the connections: the network perspective in interorganizational research. The Academy of Management Perspectives 24(1), 62-77 (2010)

26. Zaheer, A., McEvily, B., Perrone, V.: Does trust matter? Exploring the effects of interorganizational and interpersonal trust on performance. Organization Science 9(2), $141-159$ (1998) 